\title{
BMJ Open Long-term outcomes and prognostic factors in patients with treated spinal dural arteriovenous fistulas: a prospective cohort study
}

Chengbin Yang, ${ }^{1}$ Yongjie Ma, ${ }^{1}$ An Tian, ${ }^{1}$ Jiaxing Yu, ${ }^{1}$ Sichang Chen, ${ }^{1}$ Chao Peng, ${ }^{1}$ Kun Yang, ${ }^{2}$ Guilin Li, ${ }^{1}$ Chuan He, ${ }^{1}$ Ming Ye, ${ }^{1}$ Tao Hong, ${ }^{1}$ Lisong Bian, ${ }^{3}$ Zhichao Wang, ${ }^{3}$ Feng Ling, ${ }^{1}$ Hongqi Zhang (D) ${ }^{1}$

To cite: Yang C, Ma Y, Tian A, et al. Long-term outcomes and prognostic factors in patients with treated spinal dural arteriovenous fistulas: a prospective cohort study. BMJ Open 2022;12:e047390. doi:10.1136/ bmjopen-2020-047390

- Prepublication history and additional supplemental material for this paper are available online. To view these files, please visit the journal online (http://dx.doi.org/10.1136/ bmjopen-2020-047390).

Received 30 November 2020 Accepted 14 December 2021

D) Check for updates

(c) Author(s) (or their employer(s)) 2022. Re-use permitted under CC BY-NC. No commercial re-use. See rights and permissions. Published by BMJ.

${ }^{1}$ Department of Neurosurgery, Xuanwu Hospital, Capital Medical University, Beijing, China

${ }^{2}$ Evidence-based Medicine, Xuanwu Hospital, Capital Medical University, Beijing, China

${ }^{3}$ Department of Neurosurgery, Beijing Haidian Hospital, Beijing, China

Correspondence to Professor Hongqi Zhang; xwzhanghq@163.com

\section{ABSTRACT}

Objective To define the pattern of long-term clinical outcomes and prognostic factors in patients with spinal dural arteriovenous fistulas (SDAVFs).

Desgin Prospective cohort study based on constantly recruiting patients with SDAVFs in two medical centres in China.

Setting Patients with SDAVFs were recruited consecutively between March 2013 and December 2014 in two referral centres.

Participants A prospective cohort of 94 patients with SDAVFs was included in this study, and 86 patients (mean age 53.0 years, 71 men) completed the study. Patients who had previously undergone endovascular or neurosurgical treatment or had neurological dysfunction caused by other diseases or refused treatment were excluded.

Interventions All patients underwent neurosurgery or endovascular embolisation. These patients were evaluated with the modified Aminoff and Logue's Scale (mALS) 1 day before and 3,6, 12 and 72 months after treatments.

Results The duration of symptoms ranged from 0.5 to 66 months (average 12.8 months). The location of SDAVFs was as follows: $33.7 \%$ above $T 7,50.0 \%$ between/include $\mathrm{T} 7$ and $\mathrm{T} 12 \%$ and $16.3 \%$ below $\mathrm{T} 12.75$ patients $(87.2 \%)$ underwent neurosurgical treatment, and 9 patients $(10.5 \%)$ underwent endovascular treatment. 58 patients (67.4\%) exhibited an improvement in mALS of one point or greater at 72 months. Patients with less disability were more likely to improve at 72 months $(p<0.05)$. 48 patients $(55.8 \%)$ showed deterioration at 72 months compared with 12 months. $61 \%$ of the patients suffered numbness, and $22 \%$ had pain before treatment. However, $81 \%$ of patients had numbness, and $28 \%$ had pain after treatment. This deterioration was related to 1 -year mALS and age.

Conclusion Nearly two-thirds of the patients experienced clinical improvement at 72 months, and preoperative (1 day before treatment) mALS was the strongest predictor of clinical improvement. However, $55.8 \%$ of patients showed deterioration after temporary recovery. All patients with SDAVFs should accept treatment as soon as possible.

\section{BACKGROUND}

Spinal dural arteriovenous fistulas (SDAVFs) are a rare disease, although they account for
Strengths and limitations of this study

- This is a large-scale prospective cohort study of spinal dural arteriovenous fistulas (SDAVFs).

- This study provides the long-term outcomes of patients suffering SDAVFs with a 6-year follow-up

- This study lacks an analysis of clinical factors such as rehabilitation.

This study lacks imaging analysis.

$70 \%$ of spinal vascular malformations, with an annual incidence of $5-10$ cases per million persons. ${ }^{1}{ }^{2}$ Digital subtraction angiography (DSA) is the gold standard for the diagnosis of SDAVFs. ${ }^{34}$ Once diagnosed, either neurosurgery or endovascular embolisation is required for patients to avoid further deterioration. ${ }^{5}$ Previous studies suggested that the preoperative severity of disability was the most important prognostic factor. Conflicting results have been obtained regarding the relationship between age, gender and duration of symptoms prior to treatment and treatment outcome. Due to the low incidence of SDAVFs, small sample sizes and unstandardised assessments among retrospective data, previous studies of long-term clinical outcomes and prognostic factors of SDAVFs are not representative. ${ }^{6-14}$

To further understand the natural history of SDAVFs, we continued a prospective cohort study to evaluate the 6-year outcomes of patients with SDAVFs to identify major prognostic factors and long-term outcomes.

\section{METHODS}

Study design

Under the guidance of Strengthening the Reporting of Observational Studies in Epidemiology, ${ }^{15}$ we performed a prospective and 
longitudinal cohort study at two referral centres (for SDAVFs that provide neurosurgical and endovascular treatments).

\section{Participants and settings}

We prospectively collected data on patients diagnosed with SDAVFs at the cervical and thoracolumbar regions who received treatment at two referral centres between March 2013 and December 2014. All patients with SDAVFs were recruited to participate. Because lesions located in the cranialcervical region and sacral coccyx area are more complex, they were excluded from this study. Patients who previously had endovascular or neurosurgical treatment or those who had neurological dysfunction caused by other diseases or refused treatment were excluded. The data were analysed by one of three designated investigators who did not participate in the treatment process. Treatment strategies were decided by consensus after review by a team of experienced neurosurgeons and neuroradiologists.

\section{Treatment and intervention}

Spinal angiography was performed in all patients, including angiography of all segmental arteries. Most patients had underwent open surgery in which their fistulas cauterised after haemilaminectomy. Endovascular treatment was considered for patients who were assessed as high risk for general anaesthesia but did not have any arterial feeders from the radicular artery of Adamkiewicz. Onyx (ev3) was injected as close as possible to the fistula until the proximal part of the draining vein was obliterated. If endovascular treatment was unsuccessful to obliterate SDAVFs, neurosurgical treatment was performed. The functional status of the patients was assessed by a standardised scale 1 day before the procedure and 3,6 , 12 and 72 months postoperatively as long-term follow-up.

\section{Data collection}

Clinical data, including age, sex, duration of symptoms, location of fistula, spinal functional status and treatment methods, were collected. The onset of symptoms was considered to be when neurological deficits were first noticed. The preoperative spinal angiogram images were reviewed by one of two senior authors to identify the location of SDAVFs. The functional status of the patients was assessed using the modified Aminoff and Logue's Scale ${ }^{16}$ (mALS, online supplemental table 1) 1 day before the procedure and at 3, 6, 12 and 72 months postoperatively. All patients underwent DSA examination after operation and MRI. The modified Denis Scale ${ }^{17}$ (mDS, online supplemental table 2) was supplied at the 72-month follow-up to evaluate the patient's sensory impairment.

\section{Bias}

Loss to follow-up might bias the results. Eight patients were lost to follow-up; the follow-up rate was $91.5 \%$. Therefore, recall bias might affect data entry, but this was minimised by ensuring that data were entered in a timely manner.
Table 1 Baseline demographics and characteristics of patients with spinal dural arteriovenous fistula*

\begin{tabular}{|c|c|}
\hline Characteristics & Number (\%) \\
\hline Age at treatment, average (SD), years & $53.0(10.3)$ \\
\hline Men, n (\%) & $71(82.6 \%)$ \\
\hline $\begin{array}{l}\text { Time interval between symptoms and } \\
\text { treatment, average (SD), months }\end{array}$ & $12.8(12.9)$ \\
\hline$\leq 6$ months, $\mathrm{n}(\%)$ & $35(40.7 \%)$ \\
\hline $6-12 m, n(\%)$ & $23(26.7 \%)$ \\
\hline$>12 \mathrm{~m}, \mathrm{n}(\%)$ & $28(32.6 \%)$ \\
\hline \multicolumn{2}{|l|}{ Location of the fistula, $\mathrm{n}(\%)$} \\
\hline Above T7 & $29(33.7 \%)$ \\
\hline T7-T12 & $43(50.0 \%)$ \\
\hline Below T12 & $14(16.3 \%)$ \\
\hline \multicolumn{2}{|l|}{ Treatment method, n (\%) } \\
\hline Neurosurgery & $75(87.2 \%)$ \\
\hline Endovascular & $9(10.5 \%)$ \\
\hline Combination & $2(2.3 \%)$ \\
\hline \multicolumn{2}{|l|}{ Preoperative mALS, n (\%) } \\
\hline \multicolumn{2}{|l|}{ G score } \\
\hline 0 & $5(5.8 \%)$ \\
\hline 1 & $8(9.3 \%)$ \\
\hline 2 & $36(41.9 \%)$ \\
\hline 3 & $18(20.9 \%)$ \\
\hline 4 & $6(7.0 \%)$ \\
\hline 5 & $13(15.1 \%)$ \\
\hline Average (SD) & $2.6(1.36)$ \\
\hline \multicolumn{2}{|l|}{ U score } \\
\hline 0 & $10(11.6 \%)$ \\
\hline 1 & $38(44.2 \%)$ \\
\hline 2 & $24(27.9 \%)$ \\
\hline 3 & $14(16.3 \%)$ \\
\hline Average (SD) & $1.5(0.9)$ \\
\hline \multicolumn{2}{|l|}{ F score } \\
\hline 0 & $7(8.1 \%)$ \\
\hline 1 & $55(64.0 \%)$ \\
\hline 2 & $20(23.3 \%)$ \\
\hline 3 & $4(4.7 \%)$ \\
\hline Average (SD) & $1.2(0.7)$ \\
\hline
\end{tabular}

${ }^{*}$ Patient with two fistulas (T8, T10).

F, faeces; G, gait; mALS, modified Aminoff and Logue's Scale; T, thoracic; $U$, urination.

\section{Statistical analysis}

All data were descriptively presented using the mean $\pm \mathrm{SD}$ for continuous data and frequencies for categorical data (table 1). Paired t-tests (with adjustment for multiple comparisons) were used to assess differences in means for the cohort between baseline and different follow-up 
time points. Pearson $\chi^{2}$ tests were used to identify factors associated with preoperative status. Pearson $\chi^{2}$ tests and unconditional logistic regression were used to identify factors affecting clinical improvement at 72 months (6 years). Clinical improvement was defined as a decrease of at least one point on the mALS compared with baseline assessment at 72 months. In the multivariate model, age ( $\leq 55$ years or $>55$ years), sex (men/women), time interval between symptom onset and treatment ( 6 months, $>6$ months and 12 months or $>12$ months), location (above $\mathrm{T} 7, \mathrm{~T} 7-\mathrm{T} 12$ or below T12), treatment performed (neurosurgical treatment, endovascular treatment or both) and preoperative mALS were entered. The preoperative mALS was classified as follows: a total score of 0-3 indicated mild disability, a score of 4-7 indicated moderate disability and a score of 8-11 indicated severe disability. Clinical improvement was entered as the dichotomous dependent variable. Interactions were tested in the model. The OR and 95\% CI were determined for significant variables in the model. All analyses were performed by an epidemiologist using Python software (V.3.6.0 final, 2016-12-23) and SPSS software (V.23, IBM Corp.).

\section{Patient and public involvement statement}

Patients were not invited to comment on the study design and were not consulted to develop patient-relevant outcomes or interpret the results. Patients were not invited to contribute to the writing or editing of this document for readability or accuracy.

\section{RESULTS}

\section{Patient population}

The baseline demographic characteristics of these 86 patients are presented in table 2 . We initially screened 94 patients; 8 patients were excluded due to loss to follow-up $(\mathrm{n}=7)$ or death from cardiovascular accidents 3 years after treatment $(\mathrm{n}=1)$. The average follow-up time interval was 74.0 months (range $62-83$ months).

In this group of 86 patients (mean age $53.0 \pm 10.3$ years; 71 men), the average time interval between symptom onset and treatment was 12.8 months (range 0.5-66 months). The most common location for SDAVFs was the lower thoracic region (T7-12, 50\%). Before treatment, the patients presented with a median mALS of 5 (range 0-11), a median G score of 2 (range 0-5), a $\mathrm{U}$ score of 1 (range 0-3) and an F score of 1 (range 0-3). A total of 75 patients $(87.2 \%)$ underwent neurosurgical treatment, 9 patients $(10.5 \%)$ underwent endovascular

Table 2 Patients' modified Danis Scale (mDS ) at 6-year time point

\begin{tabular}{llll}
\hline & Numbness & Pain & mDS \\
\hline Mean & 2.3 & 1.4 & 3.7 \\
Range & $1-4$ & $1-5$ & $2-7$ \\
SD & 0.87 & 0.84 & 1.16 \\
\hline
\end{tabular}

treatment, and 2 patients $(2.3 \%)$ underwent neurosurgical treatment after unsuccessful endovascular treatment. In one patient, the fistula was obliterated after the first embolisation but required neurosurgery for recurrence demonstrated on 8-month follow-up angiography.

\section{Clinical outcomes}

The pattern of changes in mALS scores at different time points postoperation is presented in figures 1 and 2. It is worth noting that in the sixth year after treatment, the spinal cord function of the patients decreased compared with that at 1 year. Most patients improved in the first year after treatment. The mALS score improved the most at the 3-month evaluation after treatment. Except for the change in $\mathrm{F}$ score between 3 months and 6 months $(p=0.09)$, the difference between two adjacent follow-up time points was significant $(\mathrm{p}<0.05)$.

At the 1-year follow-up, 74 patients $(86.0 \%)$ improved their mALS, 63 patients (73.3\%) improved gait disability, 51 patients $(59.3 \%)$ improved urination function and only 38 patients $(44.2 \%)$ improved their defecation function. For patients with an exercise score of 5, only $38.5 \%$ were able to walk independently.

At the 6-year follow-up, only 58 patients (67.4\%) showed improvement in their mALS, 50 patients $(58.1 \%)$ improved gait ability, 38 patients (44.2\%) improved urination function and only 30 patients (34.9\%) improved their defecation function. Fortunately, for patients with an exercise score of $5,53.8 \%$ of patients were able to walk independently, and 1 patient improved the G score to 0 .

We compared the changes between the 6-year and the 1-year periods. Fifteen patients $(17.4 \%)$ continued to improve spinal cord function, while up to 48 patients $(55.8 \%)$ were in worse condition than they were a year ago. Fifteen patients $(17.4 \%)$ had improved gait disorders, 7 patients $(8.1 \%)$ had improved urination function and 10 patients $(11.6 \%)$ had improved defecation. Forty patients $(46.5 \%)$ had worse gait than before, 34 patients $(39.5 \%)$ had increased urination disorders and 23 patients $(26.7 \%)$ experienced defecation that was worse than before.

Since the preoperative mDS was not recorded and to ensure the reliability of the data, we only collected whether there was numbness or pain before the operation and the mDS of these patients 6 years after the operation. In this study, $61 \%$ of the patients suffered numbness, and $22 \%$ had pain before treatment. However, $81 \%$ of patients had numbness, and $28 \%$ of patients had postoperative pain. Thirty per cent of them developed numbness only after surgical treatments. Thirty-three per cent of patients had local pain before treatment (figure 3). Few patients could completely relieve their pain or numbness after treatment. At the 6 -year time point, the average $\mathrm{mDS}$ was 3.7 points (range 2-7), including a pain score of 1.4 points and a numbness score of 2.3 points (table 2 ). 
A Change of mALS before and after operation

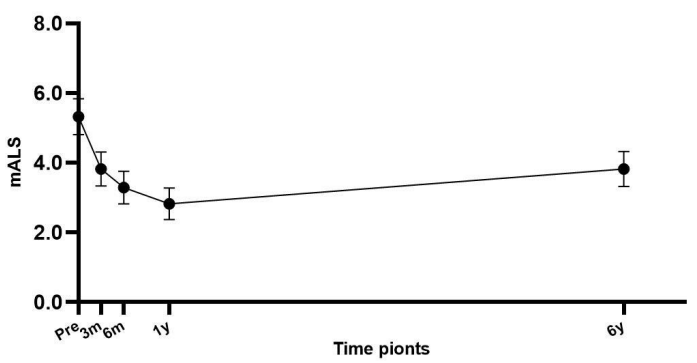

C Change of $U$ score before and after operation

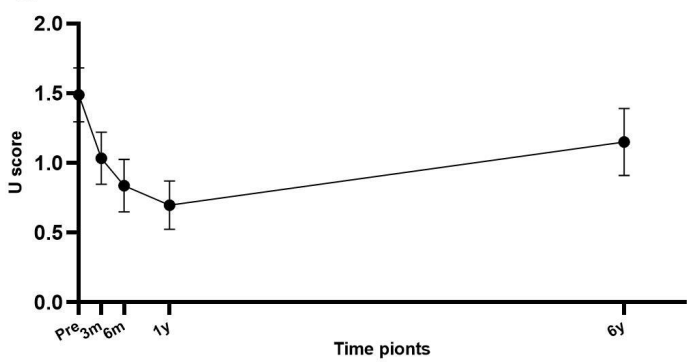

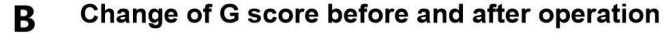

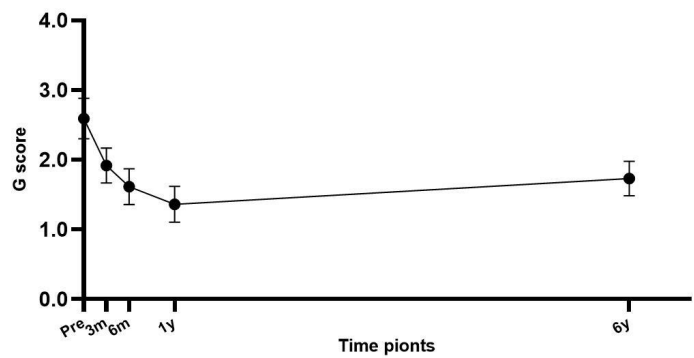

D Change of $\mathrm{F}$ score before and after operation

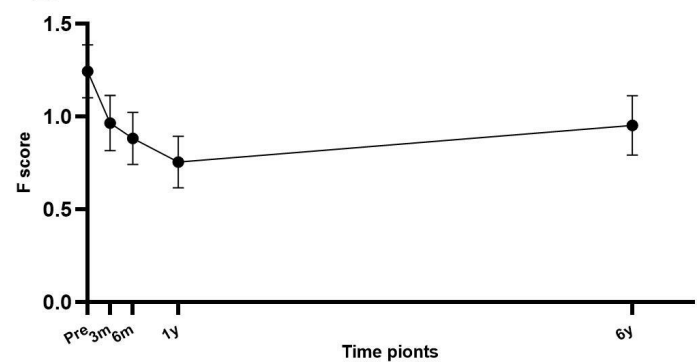

Figure 1 Compared with the baseline, the modified Aminoff and Logue's Scale (mALS) score improved at all time points. In the sixth year after surgery, the mALS decreased compared with the first year. Except for the change in $\mathrm{F}$ score between 3 months and 6 months $(p=0.09)$, the difference between two adjacent follow-up time points was significant $(p<0.05)$.

\section{Prognostic factors}

The preoperative mALS was found to be related to clinical improvement at 6 years. A higher preoperative mALS, which suggests higher spinal cord disability (score of $4-7$, OR $0.305,95 \%$ CI 0.099 to 0.936 , and score of $8-11$, OR $0.058,95 \%$ CI 0.006 to 0.557 ), suggests poor clinical improvement at 6 years. The age, duration of symptoms, location of fistula and treatment method used were not related to the outcomes (table 3). There was a trend towards an inverse relationship between age (when entered as a continuous variable) and a higher rate of clinical improvement between 6 years and 1 year $(\mathrm{p}=0.028)$.

\section{DISCUSSION}

Our study provides outcomes and long-term prognostic factors for a large patient with SDAVF cohort study by using a prospective standardised assessment method.

\section{Short-term outcome of patients with SDAVFs}

Most patients with SDAVFs can obtain better spinal cord function after neurosurgery treatment. ${ }^{18}$ Within 1 year, $74.5 \%$ of patients experienced improvement in their motor symptoms. A total of $58.5 \%$ of patients recovered urination function, and the percentage of recovered defecation function was $43.6 \%$. The improvement showed a continuing trend and was more obvious in the first 3 months.

\section{Long-term outcome of patients with SDAVFs}

In a study by Jablawi $e t$ al, clinical outcome was improved in $21 / 40(53 \%)$, stable in $11 / 40(28 \%)$ and aggravated in $8 / 40$ patients (20\%, follow-up interval 10-231 months) ${ }^{10}$ In Tacconi's study, 13/20 (63\%) patients showed a deterioration in their follow-up (interval 3-24 months) ${ }^{13}$ In our group, although there was an obvious score change between 6 years and 1 year, nearly $67.4 \%$ of patients had improved mALS compared with preoperation. A total

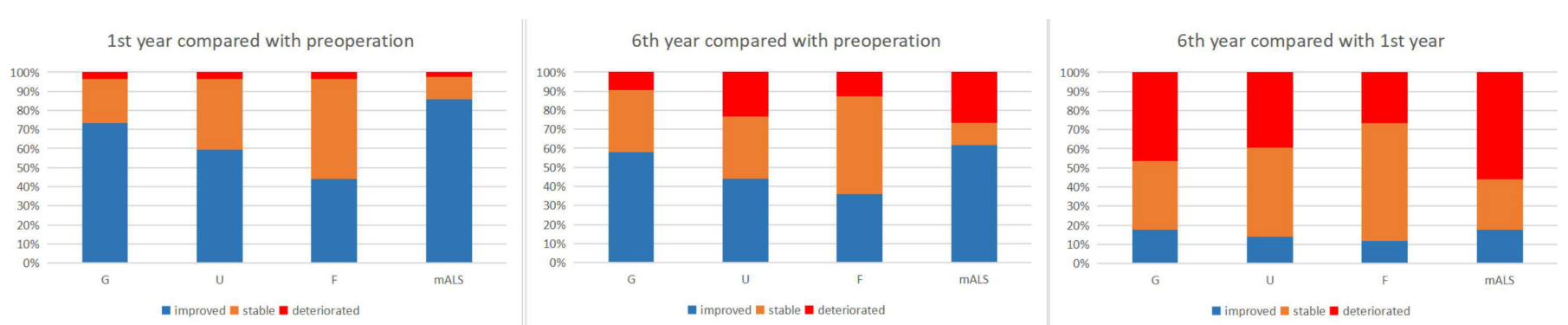

Figure 2 Red indicates deterioration, yellow indicates stability, blue indicates improvement. Compared with first year, 55.8\% of patients showed deterioration at sixth year. 


\section{Numbness}

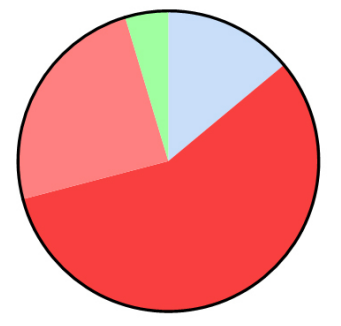

$13.95 \%$ None before or after treatment

$56.98 \%$ Begin before treatment

$24.42 \%$ Begin after treatment

4.65\% Disappear after treatment
Total $=86$

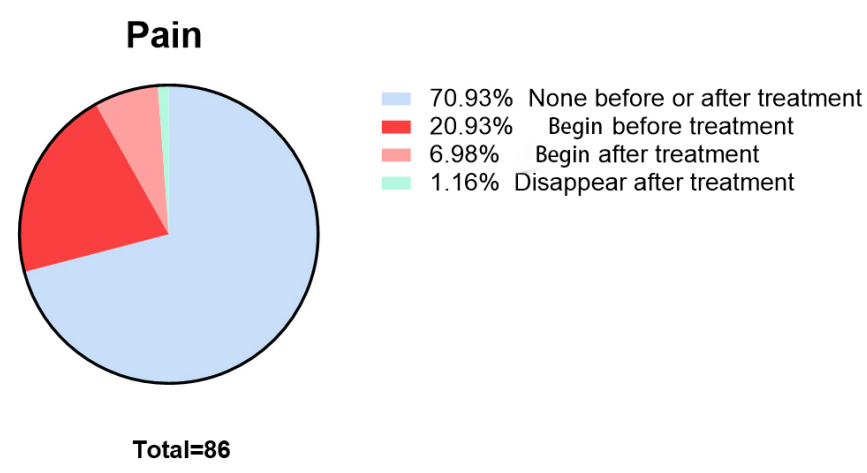

Figure 3 Eighty-one per cent of patients had postoperative limb numbness, $28.0 \%$ of patients had postoperative pain and $30 \%$ of them developed numb symptoms only after surgical treatments. Thirty-three per cent of patients had local pain symptoms before treatment. Few patients could completely relieve their pain or numbness after surgical treatment.

of $58.1 \%$ of patients improved gait disability, $44.2 \%$ of patients experienced improvement of urination function and $34.9 \%$ of patients improved their defecation function. Moreover, $81 \%$ of these patients had body numbness, and $28 \%$ of patients had pain after treatment, among which $30 \%$ had no numbness previously.

\section{Prognostic factors}

In this study, the strongest factor predicting the longterm outcome was the degree of preoperative spinal cord function, while age, sex, duration of symptoms and location of fistula were not directly correlated. Nagata et al suggested that outcome was better in younger patients. ${ }^{11}$ However, we found no correlation between age and clinical improvement at 1 or 6 years, consistent with previous studies. ${ }^{1013}$ Although some studies ${ }^{711} 14$ including ours have shown no correlation between the duration of symptoms and short-term prognosis, Tacconi et al believed that a shorter duration of symptoms could predict a better body condition. ${ }^{1012}$ SDAVFs are a type of spinal venous hypertensive disease. If not treated in time, the patient's spinal cord function will gradually decline, and even irreversible neuronal damage may occur, so the duration of symptoms may be another predictor of patient outcome. This requires the subsequent inclusion of more cases to confirm their relevance. Cenzato et al found that the location of the fistula could predict outcome; patients with a fistula between T9 and T12 improved more than those with a fistula elsewhere. ${ }^{814}$ Shinoyama et al found that in craniocervical SDAVFs, surgical treatment provides favourable long-term outcomes without a risk of recurrence. In thoracolumbar SDAVFs, irreversible structural changes, such as spinal cord atrophy, may lead to poor recovery. ${ }^{12}$ In our results, no association was found between clinical improvement and the level of fistula. In addition, multiple fistula SDAVFs are extremely rare. ${ }^{10} 1920$ We included $3(3.5 \%)$ patients with dual SDAVFs. In one patient, one fistula was on the right T8 and another on the left T10, and the draining veins were also separated. This patient showed mild disability during the first year but developed severe disability 6 years later. However, the other two patients (one fistula was located on both sides of L1 and the other fistula was located on L3 and contralateral L4) were more stable. This phenomenon may be related to the range of the segment covered by the draining vein.

The treatment (microsurgery or endovascular) that benefits patients with SDAVFs has been a controversial topic. However, the primary goal of SDAVF treatment must be the interruption of fistulas. From the perspective of avoiding fistula recurrence, the surgical treatment of SDAVFs is superior to intravascular treatment. ${ }^{12} 20$ In terms of therapeutic effects, intravascular treatment is improving. In 2004, Steinmetz et al reported a success rate of $46 \%$ in the endovascular group. In 2016, the probability of intravascular treatment performed by Sasamori $\mathrm{T}$ et al achieving complete embolisation was as high as $71.0 \%$. In our study, the success rate of endovascular treatment was $76.9 \% .^{18}$ To date, it is currently believed that neither microsurgery nor endovascular embolisation shows statistical significance with regard to outcome. ${ }^{20}$

Tacconi et al believe that preoperative functional status is related to long-term clinical outcomes. ${ }^{13}$ Our results are consistent with this scenario. Jablawi $\mathrm{F}$ et al speculated that the preoperative neurological condition was not related to long-term prognosis. ${ }^{10}$ This might due to their small sample. In our study, there were indeed cases of patients with severe disability preoperatively who achieved extremely high improvement after treatment (among patients with an exercise score of 5, 53.8\% of patients were able to walk independently at 6 years, and 1 patient's $\mathrm{G}$ score reached 0 ).

We observed that patients with SDAVFs usually have sensory dysfunction. Muralidharan et al believed that acupuncture-like sensation abnormalities in patients before surgery indicate poor clinical improvement. ${ }^{21}$ Shinoyama $\mathrm{M}$ et al found that some patients with SDAVFs have postoperative numbness or pain symptoms and new numbness or pain. ${ }^{12}$ Combined with the overall decline in spinal motor function in patients, we suspect that there are often irreversible structural changes in the spinal cord. It is widely recognised that the pathophysiology of SDAVFs is chronic hypoxia and progressive myelopathy induced by venous hypertension. ${ }^{22}$ However, venous congestion in SDAVFs does not always cause irreversible tissue destruction. The spinal 
Table 3 Factors associated with clinical improvement at 6 year (compared with preoperation state): univariate and multivariate analysis

\begin{tabular}{|c|c|c|c|c|c|c|}
\hline \multirow[b]{2}{*}{ Variable } & \multirow{2}{*}{$\begin{array}{l}\text { Patients with } \\
\text { improvement, } \\
\text { n (\%) }\end{array}$} & \multirow{2}{*}{$\begin{array}{l}\text { Patients without } \\
\text { improvement, } n \\
(\%)\end{array}$} & \multicolumn{2}{|c|}{ Univariate model } & \multicolumn{2}{|l|}{ Multivariate model } \\
\hline & & & $\chi^{2}$ & $P$ value & OR $(95 \% \mathrm{Cl})$ & $P$ value \\
\hline Age & & & 0.825 & 0.364 & 1.527 (0.611 to 3.815$)$ & 0.365 \\
\hline$\leq 55$ years & 37 & 15 & & & & \\
\hline$>55$ years & 21 & 13 & & & & \\
\hline Gender & & & 1.305 & 0.253 & 2.174 (0.560 to 8.433$)$ & 0.262 \\
\hline Men & 46 & 25 & & & & \\
\hline Women & 12 & 3 & & & & \\
\hline $\begin{array}{l}\text { Time interval between } \\
\text { symptom onset and } \\
\text { treatment }\end{array}$ & & & 1.806 & 0.405 & & \\
\hline$\leq 6$ months & 21 & 13 & & & Reference & \\
\hline $6-12$ months & 14 & 8 & & & 0.923 (0.304 to 2.802) & 0.888 \\
\hline$>12$ months & 23 & 7 & & & 0.492 (0.165 to 1.466$)$ & 0.203 \\
\hline Location of the fistula & & & 1.171 & 0.557 & & \\
\hline Above T7 & 18 & 11 & & & Reference & \\
\hline $\mathrm{T} 7-\mathrm{T} 12$ & 29 & 14 & & & 0.790 (0.295 to 2.115$)$ & 0.639 \\
\hline Below T12 & 11 & 3 & & & 0.446 (0.102 to 1.962$)$ & 0.286 \\
\hline Treatment method & & & 1.555 & 0.459 & & \\
\hline Neurosurgery & 49 & 26 & & & Reference & \\
\hline Endovascular & 7 & 2 & & & 0.538 (0.104 to 2.781$)$ & 0.460 \\
\hline Combination & 2 & 0 & & & 0.374 (0.017 to 8.070$)$ & 0.530 \\
\hline Preoperative mALS & & & 9.125 & 0.010 & & \\
\hline $0-3$ & 7 & 10 & & & Reference & \\
\hline $4-7$ & 39 & 17 & & & 0.305 (0.099 to 0.936$)$ & 0.038 \\
\hline $8-11$ & 12 & 1 & & & 0.058 (0.006 to 0.557$)$ & 0.014 \\
\hline
\end{tabular}

mALS, modified Aminoff and Logue's Scale; T, thoracic.

cord pathology in some cases is oedema due to congestion or ischaemic penumbra caused by low perfusion, which might be relieved after fistulas are cured.

\section{Late deterioration}

In our study, 48/86 (55.8\%) of the patients showed deterioration, which was similar to the findings of Cecchi et al..$^{23}$ The first cause to be considered was recrudescence. However, this has not been reported in previous surgical series.

The main causes of this reversal might be haemodynamic changes in the local vascularisation induced by the fistulas and the long period of anatomofunctional deficiency of the venous drainage. Patients might obtain significant improvement after surgical treatment, which immediately changes the venous pressure around the lesion and gradually relieves spinal cord oedema. However, late deterioration may result from neuronal loss, which is caused by venous hypertension before treatments. In our rabbit model of spinal venous hypertension, we observed neuronal demyelination and inflammatory changes. ${ }^{24} \mathrm{We}$ speculate that the temporary recovery of patients with
SDAVF is mainly due to the relief of spinal cord oedema. The inflammatory factors and autoantibodies released by necrotic neurons cause local inflammatory reactions, which persist for a long time, eventually leading to late deterioration of the patient. Durnford et $a l^{25}$ believed that these patients had a reduced neural reserve, and any future neuronal loss that might have been subclinical in normal individuals may result in clinically overt neurologic deterioration.

We analysed the existing data and found that a poor postoperative $\mathrm{mAL}$ grade at 1 year might lead to late deterioration $(\mathrm{p}=0.005,<0.01)$ (table 4 ) by setting the 1-year postoperative state as baseline. When age was entered as a continuous variable, it was related to deterioration. Furthermore, we examined the patient group characteristics, and the assessment system content included urination function. The average age reached 53 , and $4 / 5$ were men. Some diseases, such as prostate diseases in male patients, affect our analysis results. Another manifestation of worsening was that sensory systemic symptoms were aggravated 
Table 4 Factors associated with clinical improvement at 6 year (compared with 1 year after treatment): univariate and multivariate analysis

\begin{tabular}{|c|c|c|c|c|c|c|}
\hline \multirow[b]{2}{*}{ Variable } & \multirow{2}{*}{$\begin{array}{l}\text { Patients with } \\
\text { improvement, n (\%) }\end{array}$} & \multirow{2}{*}{$\begin{array}{l}\text { Patients without } \\
\text { improvement, n (\%) }\end{array}$} & \multicolumn{2}{|c|}{ Univariate model } & \multicolumn{2}{|l|}{ Multivariate model } \\
\hline & & & $\chi^{2}$ & $P$ value & OR $(95 \% \mathrm{Cl})$ & P value \\
\hline Age & & & 0.387 & 0.534 & 0.701 (0.228 to 2.153$)$ & 0.535 \\
\hline$>55$ years & 7 & 27 & & & & \\
\hline Gender & & & 1.074 & 0.300 & 1.983 (0.534 to 7.370$)$ & 0.306 \\
\hline Women & 4 & 11 & & & & \\
\hline $\begin{array}{l}\text { Time interval between } \\
\text { symptom onset and } \\
\text { treatment }\end{array}$ & & & 2.904 & 0.234 & & \\
\hline$\leq 6$ months & 3 & 31 & & & Reference & \\
\hline Above T7 & 2 & 27 & & & Reference & \\
\hline $\mathrm{T} 7-\mathrm{T} 12$ & 9 & 34 & & & 0.280 (0.056 to 1.405$)$ & 0.122 \\
\hline Below T12 & 4 & 10 & & & 0.185 (0.029 to 1.173$)$ & 0.073 \\
\hline Treatment method & & & 11.924 & 0.002 & & \\
\hline Neurosurgery & 10 & 65 & & & Reference & \\
\hline Endovascular & 3 & 6 & & & 0.308 (0.066 to 1.432$)$ & 0.133 \\
\hline Combination & 2 & 0 & & & $0.032(0.001$ to 0.716$)$ & 0.030 \\
\hline 1-year mALS & & & 10.721 & 0.005 & & \\
\hline
\end{tabular}

mALS, modified Aminoff and Logue's Scale; T, thoracic.

or newly occurred. In our study, $81 \%$ of patients had body numbness at the 6 -year time point, and $30.0 \%$ of patients had no previous numbness. The occurrence of numbness was three times more frequent than pain. Shinoyama $e t$ $a l^{12}$ found that the existence of postoperative spinal cord atrophy and a residual intramedullary hyperintense lesion in T2WI correlated with poor functional recovery, as well as worsening of neuropathic pain. The specific mechanism was not clear. Furthermore, patient work and economics and attention to the rehabilitation of the disease result in long-term variations in the rehabilitation process, which will cause certain deviations in our research.

Therefore, patients with SDAVFs must undergo surgical treatment as soon as possible; otherwise, their spinal cord function will decline gradually. The irreversible damage to the spinal cord caused by spinal venous hypertension, or any reason for delayed treatment, may also affect subsequent recovery.

\section{LIMITATIONS}

This study has some limitations. First, the investigator analysed spinal function based on mALS, which focuses only on motor and sphincter status. Sensory function development rules cannot be described. Second, there is a lack of analysis of more clinical factors for late deterioration, such as whether the patient has undergone regular rehabilitation, steroid treatment, prostate disease and so on. We continued to collect data to further verify the above factors. Finally, this study lacks imaging analysis. The imaging features on MRI have been studied. Signs of T2WI hyperintensity and flow voids were observed on MRI. Patients with enlarged draining veins (>10 spinal levels) had worse mALS scores, more extensive draining veins were associated with more spinal cord T2 hyperintensity, ${ }^{26}$ and the extent of the hyperintensity area was relevant to preoperative neurological deficits. ${ }^{27}$ Yamahata et al evaluated sagittal T2-weighted MRI scans and assessed the CEOR (the occupation ratio of the cauda equina compared with the sagittal diameter of the corresponding lumbar spinal canal) and found that there was a 
significant difference between the preoperative and postoperative values, which could be used as a criterion for evaluating surgery. T2 signal abnormalities of the spinal cord and flow voids were not associated with clinical outcomes. ${ }^{9} 1028$

\section{CONCLUSION}

This prospective cohort study shows that preoperative mALS is the strongest relevant factor for long-term outcome in patients with SDAVFs. A total of $67.4 \%$ of patients recovered after interruption of the fistula. Although the overall spinal cord function of the patients improved in the sixth year after the operation, compared with their preoperative state, a significant decrease was observed compared with the patients' optimal postoperative condition. The postoperative mALS at 1 year and patients' age is inversely related to this decline. Patients' sensory systems may also deteriorate in the long term. Therefore, patients with SDAVFs should undergo treatment (not limited to open surgery or endovascular treatment) as soon as possible, otherwise their spinal cord function will decline gradually. The irreversible damage to the spinal cord caused by spinal venous hypertension, or any reason lead to delayed treatment may also affect subsequent recovery.

\section{FUTURE EFFORTS}

There are 86 patients in our prospective cohort who continued to be followed. By constantly recruiting new participants and supplementing data, we can obtain results that more closely resemble the actual situation, which will be described and analysed in more detail later. Not all patients showed late deterioration. What are the pathological changes in the spinal cords of patients with SDAVFs that can explain this deterioration? How can late deterioration be avoided and treated? The significance of rehabilitation training for long-term outcomes needs further research.

\section{Acknowledgements We thank all the patients for cooperation.}

Contributors $\mathrm{CY}$ and $\mathrm{YM}$ contributed equally to this work and should be considered cofirst authors. CY, study concept, design, acquisition of data and guarantor. YM, study concept and design, investigator. AT, investigator. JY, investigator. SC, investigator. CP, investigator. KY, analysis and interpretation of data. GL, investigator. $\mathrm{CH}$, investigator. MY, investigator. TH, investigator. LB, investigator. ZW, director of Coordinating Center (Beijing Haidian Hospital). FL, study supervision. HZ, study supervision.

Funding This work was supported by the National Natural Science Foundation of China (Award Number: 81171165; 81671202; 82101460); Beijing Municipal Science and Technology Commission (Award Number: D161100003816001).

Disclaimer The manuscript is an original work and has not been under consideration for publication in another journal. The local ethics board of our institution approved this study. The patients or the public were not involved in the design, or conduct, or reporting, or dissemination plans of our research. We also confirm that all the listed authors have participated actively in the study, and have seen and approved the submitted manuscript. The authors have no personal financial or institutional interest in any of the drugs, materials, or devices described in this manuscript.

Competing interests None declared.
Patient consent for publication Consent obtained directly from patient(s)

Ethics approval This study was reviewed and approved by the ethics committee of Xuanwu Hospital, Capital Medical University (No.2017[101]). Participants gave informed consent to participate in the study before taking part.

Provenance and peer review Not commissioned; externally peer reviewed.

Data availability statement No data are available.

Supplemental material This content has been supplied by the author(s). It has not been vetted by BMJ Publishing Group Limited (BMJ) and may not have been peer-reviewed. Any opinions or recommendations discussed are solely those of the author(s) and are not endorsed by BMJ. BMJ disclaims all liability and responsibility arising from any reliance placed on the content. Where the content includes any translated material, BMJ does not warrant the accuracy and reliability of the translations (including but not limited to local regulations, clinical guidelines, terminology, drug names and drug dosages), and is not responsible for any error and/or omissions arising from translation and adaptation or otherwise.

Open access This is an open access article distributed in accordance with the Creative Commons Attribution Non Commercial (CC BY-NC 4.0) license, which permits others to distribute, remix, adapt, build upon this work non-commercially, and license their derivative works on different terms, provided the original work is properly cited, appropriate credit is given, any changes made indicated, and the use is non-commercial. See: http://creativecommons.org/licenses/by-nc/4.0/.

ORCID iD

Hongqi Zhang http://orcid.org/0000-0001-8136-1753

\section{REFERENCES}

1 Thron A. [Spinal dural arteriovenous fistulas]. Radiologe 2001;41:955-60.

2 Thron AK. Applications in spinal dural AV fistulas. In: Thron AK.Vascular Anatomy of the Spinal Cord:Radioanatomy as the Key to Diagnosis and Treatment. 2nd ed. Cham: Springer-Verlag International Publishing, 2016.

3 Krings T, Lasjaunias PL, Hans FJ, et al. Imaging in spinal vascular disease. Neuroimaging Clin N Am 2007;17:57-72.

4 Krings T. Geibprasert S: spinal dural arteriovenous fistulas. AJNR Am $J$ Neuroradiol 2009;30:639-48.

5 Song JK, Viñuela F, Gobin YP, et al. Surgical and endovascular treatment of spinal dural arteriovenous fistulas: long-term disability assessment and prognostic factors. J Neurosurg 2001;94:199-204.

6 Steinmetz MP, Chow MM, Krishnaney AA, et al. Outcome after the treatment of spinal dural arteriovenous fistulae: a contemporary single-institution series and meta-analysis. Neurosurgery 2004;55:77-88.

7 Wakao N, Imagama S, Ito Z. Clinical outcome of treatments for spinal dural arteriovenous fistulas: results of multivariate analysis and review of the literature. Spine 2012;37:482-8.

8 Cenzato M, Debernardi A, Stefini R, et al. Spinal dural arteriovenous fistulas: outcome and prognostic factors. Neurosurg Focus 2012;32:E11.

9 Du B, Liang M, Fan C, et al. Clinical and imaging features of spinal dural arteriovenous fistula: clinical experience of 15 years for a major tertiary hospital. World Neurosurg 2020;138:e177-82.

10 Jablawi F, Schubert GA, Dafotakis M, et al. Long-Term outcome of patients with spinal dural arteriovenous fistula: the dilemma of delayed diagnosis. AJNR Am J Neuroradiol 2020;41:357-63.

11 Nagata S, Morioka T, Natori Y, et al. Factors that affect the surgical outcomes of spinal dural arteriovenous fistulas. Surg Neurol 2006;65:563-8

12 Shinoyama M, Endo T, Takahash T, et al. Long-Term outcome of cervical and thoracolumbar dural arteriovenous fistulas with emphasis on sensory disturbance and neuropathic pain. World Neurosurg 2010;73:401-8.

13 Tacconi L, Lopez Izquierdo BC, Symon L. Outcome and prognostic factors in the surgical treatment of spinal dural arteriovenous fistulas. A long-term study. Br J Neurosurg 1997;11:298-305.

14 Cenzato M, Versari P, Righi C, et al. Spinal dural arteriovenous fistulae: analysis of outcome in relation to pretreatment indicators. Neurosurgery 2004;55:815-23.

15 von Elm E, Altman DG, Egger M, et al. The strengthening the reporting of observational studies in epidemiology (STROBE) statement: guidelines for reporting observational studies. Ann Intern Med 2007;147:573-7.

16 Aminoff MJ, Logue V. Clinical features of spinal vascular malformations. Brain 1974;97:197-210. 
17 Denis F, Armstrong GW, Searls K, et al. Acute thoracolumbar burst fractures in the absence of neurologic deficit. A comparison between operative and nonoperative treatment. Clin Orthop Relat Res 1984:189:142-9.

$18 \mathrm{Ma}$ Y, Chen S, Peng C, et al. Clinical outcomes and prognostic factors in patients with spinal dural arteriovenous fistulas : a prospective cohort study in two Chinese centres. BMJ Open 2018;8:e019800.

19 Rizvi T, Garg A, Mishra NK, et al. Metachronous double spinal dural arteriovenous fistulas. Case report and review of the literature. $J$ Neurosurg Spine 2006;4:503-5.

20 Krings T, Mull M, Reinges MHT, et al. Double spinal dural arteriovenous fistulas: case report and review of the literature. Neuroradiology 2004;46:238-42.

21 Muralidharan R, Mandrekar J, Lanzino G, et al. Prognostic value of clinical and radiological signs in the postoperative outcome of spinal dural arteriovenous fistula. Spine 2013;38:1188-93.

22 Hurst RW, Kenyon LC, Lavi E, et al. Spinal dural arteriovenous fistula: the pathology of venous hypertensive myelopathy. Neurology 1995;45:1309-13.
23 Cecchi PC, Musumeci A, Rizzo P, et al. Late deterioration of neurologic function in patients surgically treated for spinal dural arteriovenous fistulas. Surg Neurol 2009;72:257-61.

24 Zhang HQ, Chen T, S S W. The pathophysiology of venous hypertensive myelopathy-study of an animal model. Journal of Neurosurgery: Spine 2013;19:485-91.

25 Durnford AJ, Hempenstall J, Sadek AR, et al. Degree and duration of functional improvement on long-term follow-up of spinal dural arteriovenous fistulae occluded by endovascular and surgical treatment. World Neurosurg 2017;107:488-94.

26 Hetts SW, Moftakhar P, English JD, et al. Spinal dural arteriovenous fistulas and intrathecal venous drainage: correlation between digital subtraction angiography, magnetic resonance imaging, and clinical findings. J Neurosurg Spine 2012;16:433-40.

27 Horikoshi T, Hida K, Iwasaki Y, et al. Chronological changes in MRI findings of spinal dural arteriovenous fistula. Surg Neurol 2000;53:243-9.

28 Fugate JE, Lanzino G, Rabinstein AA. Clinical presentation and prognostic factors of spinal dural arteriovenous fistulas: an overview. Neurosurg Focus 2012;32:E17. 